\section{Cureus}

\title{
A Case of Transient ST Elevation and Polymorphic Tachycardia without Angina Diagnosed by Holter Monitoring
}

\author{
Ali Farooq ${ }^{1}$, Fahad Alqahtani ${ }^{2}$, Almoutassim Trabulsi ${ }^{3}$, Akram Kawsara ${ }^{3}$, Mohamad \\ Alkhouli $^{4}$ \\ 1. Internal Medicine, West Virginia University/Charleston Area Medical Center, Charleston, USA 2. \\ Division of Cardiovascular Disease, West Virginia University School of Medicine/Ruby Memorial \\ Hospital, West Virginia, USA 3. Division of Cardiovascular Disease, West Virginia University School of \\ Medicine/Ruby Memorial Hospital 4. Division of Cardiovascular Disease, West Virginia University School \\ of Medicine/Ruby Memorial Hospital, morgantown, USA
}

$\square$ Corresponding author: Ali Farooq,dr.aliumair786@gmail.com

Disclosures can be found in Additional Information at the end of the article

\section{Abstract}

We report the case of 52-year-old female with recurrent episodes of palpitations and dizziness. Holter monitoring revealed transient ST elevations followed by episodes of polymorphic ventricular tachycardia associated with episodes of palpitations and dizziness. Coronary angiography revealed mildly irregular right coronary artery with $90 \%$ stenosis. The patient underwent percutaneous coronary intervention with successful placement of a stent to the mid-right coronary artery. The patient has been followed closely over a period of 12 months. There haven't been any recorded episodes of tachycardia, and the patient has remained symptom-free.

Categories: Cardiology, Internal Medicine

Keywords: polymorphic ventricular tachycardia, holter monitor, silent myocardial infarction

\section{Introduction}

The diagnosis of acute myocardial infarction is mainly based on the electrocardiogram (EKG) findings of ST elevations or new onset left bundle branch block, which is supported by the clinical presentation and positive biomarkers when present. Although anginal episodes (chest pain, dyspnea, and diaphoresis) are the cardinal symptoms of acute myocardial, silent myocardial infarction (SMI) occurs far more frequently than angina episodes in patients with stable coronary artery disease. In a study of 105 patients with stable angina, $40 \%$ of patients

Received 05/13/2017

Review began 05/17/2017 Review ended 05/19/2017 Published 05/25/2017

\section{(c) Copyright 2017}

Farooq et al. This is an open access article distributed under the terms of the Creative Commons Attribution License CC-BY 3.0., which permits unrestricted use, distribution, and reproduction in any medium, provided the original author and source are credited. have frequent episodes of SMI on ambulatory EKG monitoring [1]. We report a case of transient ST-elevation and polymorphic ventricular tachycardia without angina diagnosed by Holter monitoring.

\section{Case Presentation}

A 52-year-old female with a history of hypertension, hyperlipidemia, and Raynaud's syndrome but no prior history of coronary artery disease presented with recurrent episodes of palpitations and dizziness. Clinical examination and initial investigations were normal. The initial 12-lead ECG showed sinus rhythm. Echocardiogram, chest X-ray, routine biochemical, troponins, and hematological analyses were normal. A Holter monitor obtained for further evaluation revealed transient ST elevations followed by significant episodes of polymorphic 


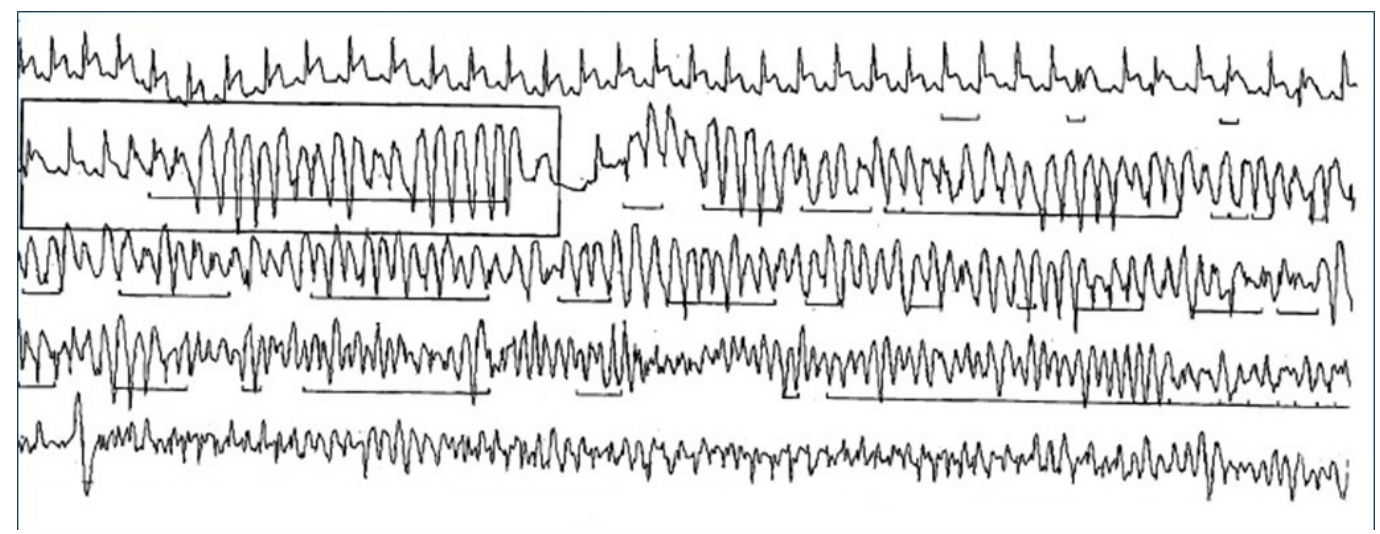

FIGURE 1: Fragment from 24-hour Holter monitor showing ST elevation followed by polymorphic ventricular tachycardia.

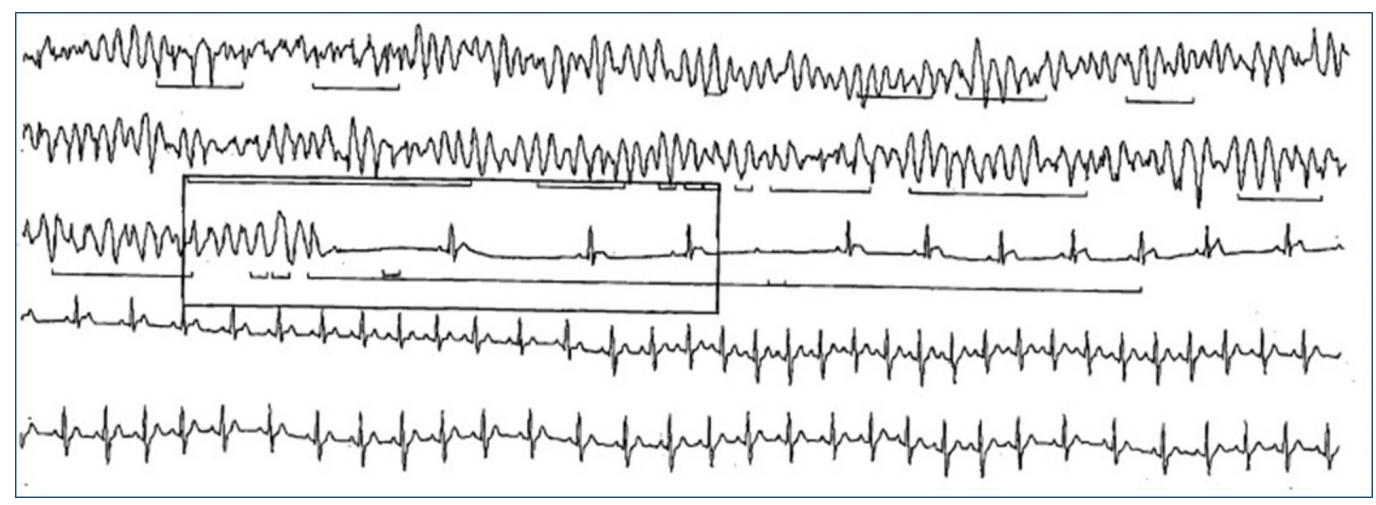

FIGURE 2: Fragment from 24-hour Holter monitor showing polymorphic ventricular tachycardia and Mobitz Type II atrioventricular block followed by sinus tachycardia.

Surprisingly, no complaint of angina was reported during the period of monitoring. The palpitations and dizziness corresponded to episodes of fast polymorphic ventricular tachycardia. The patient was admitted for further evaluation. Repeated EKG showed nonspecific changes in the inferior leads. Cardiac biomarkers and electrolytes were within normal limits. Coronary angiography demonstrated a mild right coronary artery irregularity with a $90 \%$ focal lesion with thrombus (Figure 3). 


\section{Cureus}

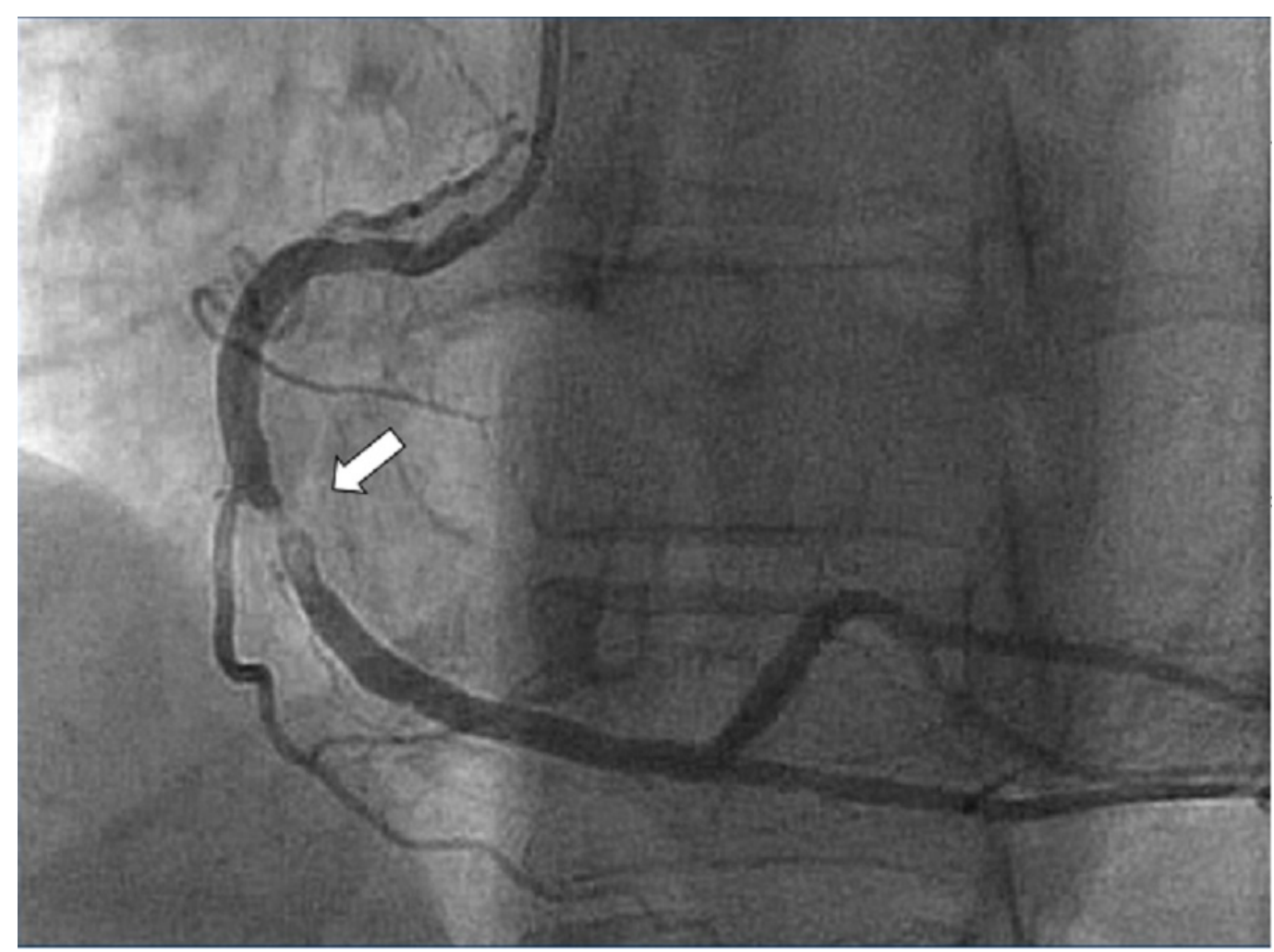

\section{FIGURE 3: Coronary angiography demonstrating mild right coronary artery irregularity with a $90 \%$ focal lesion with thrombus.}

She underwent percutaneous coronary intervention with the successful placement of a stent to the mid-right coronary artery as well as aspiration thrombectomy. The patient has been followed closely over a period of 12 months. There haven't been any recorded episodes of tachycardia and patient has remained symptom-free.

\section{Discussion}

It is well described that a certain group of patients does not display the typical symptoms of myocardial infarction. Elderly patients, diabetics, and those with previous coronary artery bypass graft surgery are at high risk for SMI [2]. The diagnoses can sometimes become challenging when the patient is asymptomatic or presents with atypical symptoms [3-4]. Ambulatory EKG monitoring can be used as a diagnostic test for detecting SMI in high-risk patients. It has improved the likelihood of recording ischemic and arrhythmic episodes during routine daily activities out of the hospital setting.

Some previous reports showed Holter recordings of ST-segment elevations and ventricular arrhythmias secondary to vasospastic angina. A case of sudden death secondary to vasospastic angina during Holter monitoring has been reported; ventricular fibrillation occurred after several ventricular premature beats following ST-segment elevation [5]. Another similar case of polymorphic ventricular tachycardia degenerating in ventricular fibrillation has been reported that occurred during Holter recording in a patient with recurrent vasospastic angina and normal coronary arteries [6].

A high index of suspicion is needed, especially in high-risk patients. SMI, when detected during 
ambulatory monitoring, predicts advanced multivessel coronary artery disease. In a study of 439 patients with SMI, $75 \%$ of patients were found to have multivessel coronary artery disease on coronary angiography [7]. There is evidence in the literature showing a strong association of SMI with increased cardiac mortality [8].

\section{Conclusions}

Our case endorses that SMI can be observed in patients without a history of known coronary artery disease. We think that in the rare clinical situation when the diagnosis is in doubt, SMI should be ruled out by Holter monitoring since SMI has a strong association with cardiac mortality. Early detection and initiation of therapy with medical management or revascularization in appropriate settings may improve prognosis in this patient population.

\section{Additional Information}

\section{Disclosures}

Human subjects: Consent was obtained by all participants in this study. Conflicts of interest: In compliance with the ICMJE uniform disclosure form, all authors declare the following: Payment/services info: All authors have declared that no financial support was received from any organization for the submitted work. Financial relationships: All authors have declared that they have no financial relationships at present or within the previous three years with any organizations that might have an interest in the submitted work. Other relationships: All authors have declared that there are no other relationships or activities that could appear to have influenced the submitted work.

\section{References}

1. Deedwania P, Carbajal E: Prevalence and patterns of silent myocardial ischemia during daily life in stable angina patients receiving conventional antianginal drug therapy. Am J Cardiol. 1990, 65:1090-96. 10.1016/0002-9149(90)90319-V

2. Cho JY, Jeong MH, Ahn YK, et al.: Comparison of outcomes of patients with painless versus painful ST-segment elevation myocardial infarction undergoing percutaneous coronary intervention. Am J Cardiol. 2012, 109:337-43. 10.1016/j.amjcard.2011.09.017

3. Cosson E, Guimfack M, Paries J, et al.: Are silent coronary stenoses predictable in diabetic patients and predictive of cardiovascular events?. Diabetes Metab. 2003, 29:470-76. 10.1016/S1262-3636(07)70060-5

4. Cosson E, Guimfack M, Paries J, et al.: Prognosis for coronary stenoses in patients with diabetes and silent myocardial ischemia. Diabetes Care. 2003, 26:1313-14. 10.2337/diacare.26.4.1313

5. Tsurukawa T, Kawabata K, Miyahara K, et al.: Sudden death during Holter electrocardiogram monitoring in a patient with variant angina. Intern Med. 1996, 35:966-69. 10.2169/internalmedicine.35.966

6. Arias MA, Sánchez AM, Fajardo A: Sudden cardiac death during Holter recording in a patient with vasospastic angina. Int J Cardiol. 2007, 118:e60-62. 10.1016/j.ijcard.2006.12.071

7. Sharaf BL, Williams DO, Miele NJ, et al.: A detailed angiographic analysis of patients with ambulatory electrocardiographic ischemia: results from the Asymptomatic Cardiac Ischemia Pilot (ACIP) study angiographic core laboratory. J Am Coll Cardiol. 1997, 29:78-84. 10.1016/S0735-1097(96)00444-5

8. Sajadieh A, Nielsen OW, Rasmussen V, et al.: Prevalence and prognostic significance of dailylife silent myocardial ischaemia in middle-aged and elderly subjects with no apparent heart disease.. Eur Heart J. 2005, 26:1402-1409. 10.1093/eurheartj/ehi169 